\title{
Metodologia de resolução de problemas: contribuições para o ensino de matemática financeira com alunos da educação de jovens e adultos
}

\author{
Problem solving methodology: contributions to the teaching of financial mathematics \\ with students of youth and adult education
}

\author{
Vanilde Bisognin \\ vanildebisognin@gmail.com
}

Tatiele Miron

tatielemiron@yahoo.com.br

\begin{abstract}
Resumo
Este artigo relata um trabalho investigativo com uma turma de vinte alunos da segunda etapa da EJA (Educação de Jovens e Adultos) de um colégio privado na cidade de Ijuí/RS. O objetivo da investigação foi investigar as potencialidades pedagógicas da metodologia de Resolução de Problemas no ensino de Matemática Financeira, associada ao uso de objetos de aprendizagem disponíveis em um ambiente virtual de aprendizagem. Neste trabalho, de caráter qualitativo, foi utilizada, como instrumento de coleta de dados, a observação participante, registrada por meio de um diário de campo, no qual foram relatados todos os acontecimentos ocorridos em classe, bem como documentos produzidos nas resoluções dos problemas. Os resultados apontaram que o uso de objetos de aprendizagem, juntamente com a proposição de problemas que fazem parte da vida dos alunos, potencializou a compreensão dos conceitos.
\end{abstract}

Palavras-chave: Resolução de problemas; Matemática Financeira; Educação de Jovens e Adultos.

\begin{abstract}
This article reports a research work with a group of twenty students of the second stage of EJA (Youth and Adult Education) of a private school in the city of Ijuí / RS. The aim of the research was to investigate the pedagogical potential of Problem Solving methodology in Financial Mathematics teaching, associated with the use of learning objects, available in a virtual learning environment. In this study, of qualitative character, participant observation recorded by means of a diary was used as data collection instrument, in which all events in class were reported, as well as documents produced in the resolution of problems. The results showed that the use of learning objects, along with the proposition of problems which are part of students' lives, enhanced the understanding of the concepts.
\end{abstract}

Keywords: Problem Solving; Financial Mathematics; Youth and Adult Education.

\section{Introdução}

Ao analisar os Parâmetros Curriculares Nacionais para o Ensino Fundamental e Médio, observa-se que estes recomendam trabalhar conteúdos que envolvem a Matemática Financeira. Porém, apesar das recomendações constantes nos documentos oficiais, este tema é pouco explorado nas aulas de Matemática, embora faça parte do cotidiano das pessoas, especialmente na tomada de decisão diante de propostas comerciais que são apresentadas nas mais variadas situações de compras de bens ou de investimentos.

A Matemática Financeira trata de problemas do mundo financeiro que envolvem problemas relacionados com o controle e gerenciamento do orçamento doméstico e do cartão 
de crédito, empréstimos, seguros e investimentos, entre outros, e que requerem habilidade e conhecimento para que os cidadãos possam tomar decisões mais acertadas em suas vidas.

Apesar da importância do tema para o dia a dia das pessoas, na escola ele é, em geral, ignorado pela maioria dos professores e também nos livros didáticos utilizados nos níveis fundamental e médio. Pesquisas como a de Vieira (2010) têm mostrado que os tópicos de Matemática Financeira, na Educação Básica, têm sido esquecidos e não são valorizados no currículo das escolas. Além disso, há um grande despreparo dos professores para trabalhar este conteúdo e, com isso, na sala de aula perde-se a oportunidade de explorar situações reais e desafiadoras do dia a dia dos alunos.

Nos Parâmetros Curriculares Nacionais (PCN) para o Ensino Fundamental (BRASIL, 1998), alguns tópicos aparecem recomendados apenas na "Conexão entre os conteúdos" e não como uma recomendação central. Nos Parâmetros Curriculares Nacionais para o Ensino Médio (BRASIL, 2000), é recomendado apenas que:

uma das formas significativas para dominar a Matemática é entendê-la aplicada na análise de índices econômicos e estatísticos, nas projeções políticas ou na estimativa da taxa de juros, associada a todos os significados pessoais, políticos e sociais que números dessa natureza carregam. (p. 77)

Portanto, a Educação Financeira não é uma preocupação central tanto da escola como dos professores e das recomendações da legislação para os diferentes níveis de ensino. Também, de acordo com as Diretrizes Curriculares do Ensino Médio (BRASIL, 2000), está estabelecido que, ao final do Ensino Médio, espera-se que os alunos saibam usar a Matemática para: resolver problemas práticos do cotidiano; modelar situações que envolvem outras áreas de conhecimentos e percebam que a Matemática é um conhecimento organizado e historicamente construído. Nestes casos, conteúdos de Matemática Financeira respondem as recomendações dessas diretrizes.

Diante de um consumo que pode se tornar avassalador, é imprescindível o domínio de conteúdos básicos de Matemática Financeira para que cada cidadão possa gestar com propriedade seu orçamento, fazendo escolhas adequadas, toda a vez que fizer uma compra, seja a vista ou a prazo, um financiamento, etc... Não há dúvida de que o ensino da Matemática Financeira é indispensável para a formação de cidadãos atuantes e críticos na sociedade, que saibam calcular, medir, raciocinar, argumentar e comparar as informações.

Por outro lado, os conteúdos relacionados com questões financeiras permitem trabalhar problemas do cotidiano dos alunos que podem motivá-los a estudar e a dar sentido à Matemática. O presente artigo aborda alguns conteúdos relacionados com a Matemática Financeira em uma turma na segunda etapa da Educação de Jovens e Adultos (EJA) do 
Colégio Frei Matias, no município de Ijui-RS, por meio da metodologia de Resolução de Problemas.

\title{
Algumas considerações teóricas
}

Ao tratar de Resolução de Problemas, a primeira questão que é colocada é o que é um problema. Para Onuchic (1999), um problema é: "[...] tudo aquilo que não se sabe fazer mas que se está interessado em resolver" (p.215). Para Dante (1991), "problema é a descrição de uma situação onde se procura algo desconhecido e não se tem previamente nenhum algoritmo que garanta sua solução" (p. 13).

Pozo e Echeverria ( 1998), ao tratarem de Resolução de Problemas, argumentam que:

\begin{abstract}
A solução de problemas baseia-se na apresentação de situações abertas e sugestivas que exijam dos alunos uma atitude ativa ou um esforço para buscar suas próprias respostas, seu próprio conhecimento. $\mathrm{O}$ ensino baseado na solução de problemas pressupõe promover nos alunos o domínio de procedimentos, assim como a utilização de conhecimentos disponíveis, para dar respostas a situações variáveis e diferentes. (p. 09)
\end{abstract}

Embora com diferentes concepções, pesquisas de diversos autores, entre os quais Pozo e Echeverria (1998), Diniz,( 2001), Van de Walle (2009), Onuchic (1999), entre outros, destacam as significativas contribuições da metodologia de Resolução de Problemas para o estudo de conteúdos de Matemática, tanto para a introdução de novos conhecimentos quanto para salientar a sua aplicabilidade. Assim, devido aos resultados positivos que as pesquisas têm mostrado, justifica-se a utilização desta metodologia de ensino para o estudo de conteúdos de Matemática Financeira.

Para a condução de um trabalho investigativo com uso do que denominam "Metodologia de Ensino-Aprendizagem-Avaliação de Matemática através da Resolução de Problemas", Onuchic e Allevato (2009, p. 177) sugerem alguns passos que podem auxiliar o professor no trabalho com os conteúdos selecionados em sala de aula: $1^{\circ}$ ) Formar grupos e entregar a atividade; $2^{\circ}$ ) Observar e incentivar; $3^{\circ}$ ) Auxiliar nos problemas secundários; $4^{\circ}$ ) Registrar as resoluções na lousa; $5^{\circ}$ ) Realizar uma plenária; $6^{\circ}$ ) Buscar um consenso; $7^{\circ}$ ) Formalizar o conteúdo.

Sobre o uso de tecnologias educacionais no âmbito dos cursos superiores, especialmente de formação de professores, Masetto et al.(2007) argumentam: "Em educação escolar, por muito tempo - e eu diria mesmo, até hoje -, não se valorizou adequadamente o uso de tecnologia visando a tornar o processo de ensino-aprendizagem mais eficiente e mais eficaz.” (p.135). Enfatizam também: 
Nos próprios cursos do ensino superior, o uso de tecnologia adequada ao processo de aprendizagem é variada para motivar o aluno não é tão comum, o que faz com que os novos professores do ensino fundamental e médio, ao ministrarem suas aulas, praticamente copiem o modo de fazê-lo e o próprio comportamento de algum de seus professores de faculdade, dando aula expositiva e, às vezes, sugerindo algum trabalho em grupo com pouca ou nenhuma orientação (p. 135).

No nível de ensino em que este estudo foi desenvolvido, verificou-se que tanto o conteúdo de Matemática Financeira quanto o uso de calculadoras e do computador foram motivadores para os alunos no estudo da Matemática.

A utilização das mídias tecnológicas como ferramentas de auxílio nos processos de ensino e aprendizagem de Matemática vem ganhando destaque nas escolas. No artigo 36 da Lei de Diretrizes e Bases 9394/96, no seu primeiro parágrafo encontramos que,

os conteúdos, as metodologias e as formas de avaliação devem ser organizadas de tal forma que ao final do Ensino Médio o educando demonstre: domínio dos princípios científicos e tecnológicos que presidem a produção moderna. (BRASIL, 1996).

Freitas e Bittar (2004, apud FERREIRA et al., 2009, p. 18) apontam, entre outras vantagens do uso de tecnologias no ensino: "conseguir informações de fácil acesso e comunicação à distância, maior agilidade na realização das tarefas, novas possibilidades para construção do conhecimento auxiliando na elaboração de conceitos."

Podemos ainda acrescentar que uma das maiores vantagens desta associação entre as tecnologias e o estudo da Matemática é conseguir mostrar aos alunos que existem outras maneiras para estudar essa disciplina.

No trabalho desenvolvido, foi utilizado um ambiente de aprendizagem chamado MAISUNIFRA (www.maisunifra.com.br), em que constam diferentes objetos de aprendizagem envolvendo conteúdos de Matemática, Física, Química, Português, Literatura, Nanotecnologia. Neste ambiente é possível encontrar, além de objetos de aprendizagem, vídeos, palestras, entrevistas e atividades diversas, com que o estudante pode interagir constantemente. O MAISUNIFRA tem o status de rede social sobre conhecimento acadêmico e está disponível livremente para qualquer usuário.

Neste trabalho, utilizaram-se os objetos de aprendizagem relacionados com conteúdos de Matemática Financeira, especialmente os que tratam de juros simples e compostos. Nesses objetos, são disponibilizadas atividades com campos em branco para que os alunos possam digitar a resposta e possam clicar e visualizar a correção; se for preciso, têm a opção de clicar para pedir orientação. Os objetos incluem tabelas e gráficos que mostram a evolução do montante e do juro em relação ao tempo, são apresentadas animações prontas de gráficos de 
barras representando a composição do montante simples e composto e a comparação entre eles.

\section{O percurso do trabalho investigativo}

O trabalho de campo aqui relatado foi desenvolvido em uma turma de um colégio público do município de Ijuí-RS e constou de uma aplicação de uma sequência didática contendo problemas de Matemática Financeira relacionados com o cotidiano dos alunos, com que se procurou explorar o desenvolvimento da capacidade de resolução de problemas. Os alunos estavam cursando a segunda etapa da EJA, em que deveriam ser trabalhados, entre outros conteúdos, a Matemática Financeira. Estes alunos, que totalizavam um grupo de vinte, tinham idades entre dezoito e cinquenta e seis anos, o que tornou a turma bastante heterogênea.

Diante de tal circunstância, o educador buscou no uso da tecnologia uma opção para tornar o ensino mais atrativo e motivador para os alunos e fazer com que eles saíssem da posição de meros receptores de informação para se tornarem sujeitos e participantes da construção dos conceitos a serem trabalhados. Ao trabalhar alguns conteúdos de Matemática Financeira por meio da Resolução de Problemas, usamos a calculadora científica e o laboratório de informática da escola, onde, por meio da internet, acessamos material disponível no MAISUNIFRA, que trata dos sistemas de juros simples e compostos.

Os resultados da investigação foram obtidos por meio das observações participantes, realizadas durante a aplicação das três unidades didáticas planejadas com situações-problema, relacionadas com o cotidiano dos alunos e registradas no diário de campo da pesquisadora, bem como das gravações e das atividades desenvolvidas em cada grupo e recolhidas ao término de cada encontro.

Inicialmente a turma foi dividida em quatro grupos de cinco alunos, os quais foram chamados de G1 (Grupo 1, cujos alunos são indicados por A1...A5), G2 (Grupo 2, os alunos indicados por B1...B5), G3 (Grupo 3, os alunos indicados por C1...C5) e G4 (Grupo 4, os alunos indicados por D1...D5). No trabalho no laboratório de informática, os alunos trabalharam em duplas.

A maioria dos alunos são trabalhadores, tais como pedreiros, pintores, mecânicos, empregados domésticos,, etc...; foi possível perceber que, em geral, eles possuíam um conhecimento básico sobre Matemática Financeira e informática.

Quando perguntados sobre o que sabiam sobre juros, alguns responderam que tinha sido "lááá no Ensino Fundamental”, expressando que muito tempo havia se passado e que, 
consequentemente, as lembranças eram poucas. O aluno A3 complementou dizendo: "eu lembro que tinha uma fórmula para encontrar o juro; era alguma coisa dividida por 100...”. Outros colegas concordaram com ele, falando: "é isso mesmo, mas tinha mais coisa, havia uma que aparecia um expoente, essa era horrivel..."

Estas falas demonstram que este conteúdo foi ensinado, possivelmente por meio de fórmulas seguidas de listas de exercícios para que os alunos as aplicassem. Neste processo, o raciocínio e a interpretação ficaram "sufocados" pela automaticidade da aplicação das fórmulas anteriormente ensinadas.

Neste contexto, efetivamente parece que não foi levada em conta a recomendação dos PCN do Ensino Fundamental, de que "é necessário trabalhar situações-problema sobre a Matemática Comercial e Financeira" (BRASIL, 1998, p. 86), pois se assim fosse, alguns alunos teriam mencionado mais do que vagas lembranças de fórmulas incompletas, quando lhes perguntado quanto ao estudo deste conteúdo.

A sequencia didática apresentou problemas que envolveram os conteúdos de juros simples e compostos e foi desenvolvida em três encontros. O primeiro foi desenvolvido no laboratório de informática da escola, em que os alunos tiveram a oportunidade de interagir com os objetos de aprendizagem sobre juros, constantes no ambiente virtual MAISUNIFRA no endereço http://www.maisunifra.com.br e teve a duração de quatro horas-aula, com o objetivo de construir o conceito de juro simples e composto. Neste ambiente, foram trabalhadas várias situações-problema envolvendo os conceitos de juros simples e compostos. Os alunos tiveram a oportunidade de interagir com objetos de aprendizagem e resolver problemas, de forma interativa, reunidos em duplas. É importante registrar que a escola possui um laboratório de informática composto de 20 computadores e ligados a internet. Todas as disciplinas usam o laboratório para o desenvolvimento de atividades e, portanto, todos os alunos possuem conhecimento razoável de informática.

Neste ambiente virtual, os alunos foram convidados a responder as seguintes questões:

a) O que é juro simples e juro composto?

b) Qual é a diferença entre eles?

c) Como são calculados?

Para responder as perguntas, os alunos acessaram a página do ambiente MAISUNIFRA e assistiram os vídeos disponíveis que tratam do conteúdo de juros simples e compostos, estudaram os exemplos e resolveram os problemas lá propostos, de forma interativa. A professora desempenhou o papel de moderadora, interagindo com cada grupo, questionando e auxiliando-os no manuseio dos objetos. 
As figuras abaixo mostram os gráficos que fazem parte do objeto de aprendizagem sobre juros.

Figura 1: Juro simples

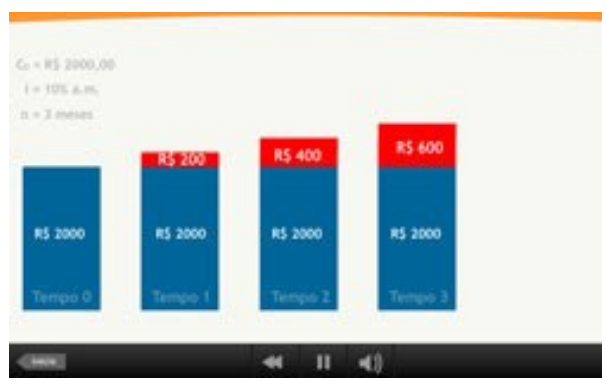

Fonte: maisunifra.com.br
Figura 2: Juros compostos

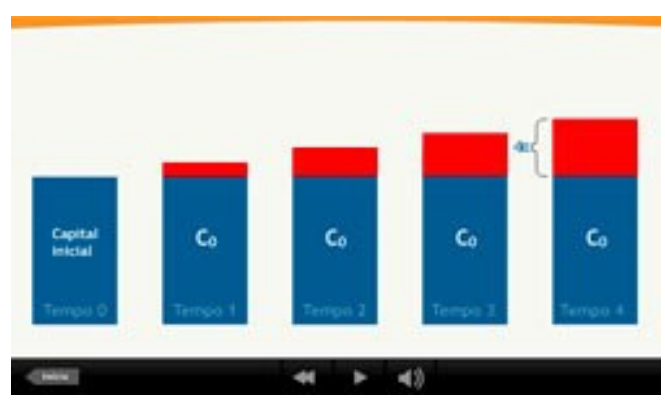

Fonte: maisunifra.com.br

Ao final do encontro, foi realizada uma plenária e os alunos, conduzidos pela professora, formalizaram os conceitos de juros e estabeleceram as fórmulas de cálculo e a comparação entre eles. Concluíram que: o Juro simples é calculado sempre sobre o capital inicial e o composto sobre o capital do período anterior.

Esta resposta foi obtida por meio da visualização do modelo interativo disponibilizado no ambiente.

Figura 3: Juro e montante composto

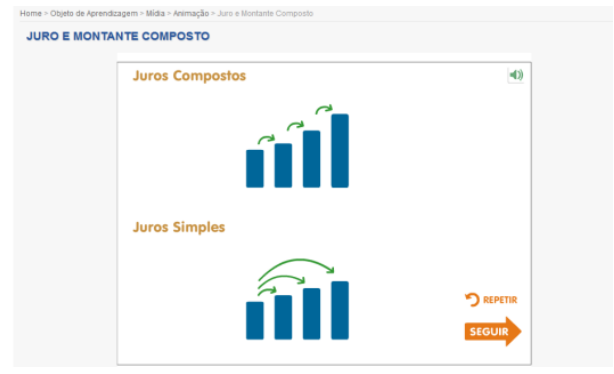

Fonte:maisunifra.com.br
Figura 4: Montante composto

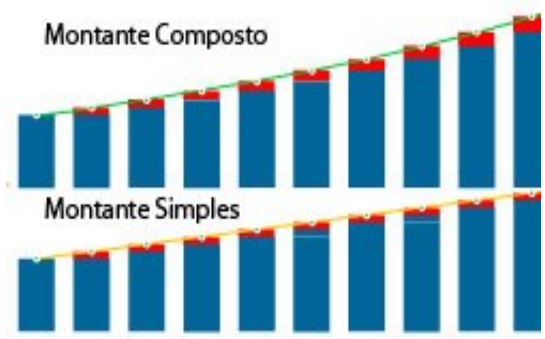

Fonte:maisunifra.com.br

No ambiente MAISUNIFRA, também são disponibilizas atividades interativas nas quais o aluno pode completar tabelas, visualizar a construção gráfica da evolução dos juros e montantes, tanto simples quanto compostos e resolver problemas envolvendo estes conceitos.

Os alunos comentaram:

A1: "Eu nunca pensei que poderia estudar matemática com informática..."

B2: "Gostei de estudar vendo os vídeos e acompanhando a fala do professor.."

C1: "A visualização da evolução do montante em cada situação ficou muito clara para mim." 
O segundo e terceiro encontros tiveram a duração de quatro e de duas horas-aula, respectivamente, e foram trabalhados problemas que envolveram o estudo dos juros simples e compostos. Foram apresentadas situações em que temos que escolher entre comprar à vista ou a prazo e teve por objetivos: identificar a presença dos juros embutidos nas compras a prazo; decidir a melhor forma de comprar, à vista ou parcelado, diante das diversas situações cotidianas. Este trabalho foi aplicado na sala de aula com os alunos reunidos em grupos, seguindo-se os passos da metodologia de Resolução de Problemas, de acordo com Onuchic e Allevato (2009). Essas aulas também contemplaram três atividades extraclasses, as quais foram resolvidas pelos alunos e postadas via internet, na plataforma de ensino que o colégio possui.

No segundo encontro foram trabalhados os problemas a seguir:

\section{Situação-Problema 1:}

a) Qual o montante resultante da aplicação, a juros simples, de $\mathrm{R} \$ 7.000,00$ à taxa de $10,5 \%$ ao ano, durante 145 dias?

b) Qual o capital que, aplicado a juros simples de 1,2\% ao mês, rende $\mathrm{R} \$ 3.500,00$ de juros em 75 dias.

c) Se a taxa de uma aplicação é de $15 \%$ ao ano, quantos meses serão necessários para dobrar um capital aplicado através da capitalização simples?

O objetivo desta questão era que os estudantes percebessem que, se um capital for aplicado por alguns dias, meses ou anos, a taxa que incide sobre ele deve estar de acordo com este tempo.

Os alunos leram o problema e, de imediato, tentaram traçar uma estratégia de resolução. A dúvida inicial foi observada em relação à taxa. O aluno A3 ponderou:

A3: deve ter uma maneira de transformar essa taxa de anual para mensal e diária, aí não terá problema. Basta aplicar o que já vimos sobre juros e montante simples.

Professora: pensem nisso.

Após estas considerações os alunos não tiveram problemas na busca da solução. Percebeu-se que os conceitos de juros simples e compostos, trabalhados na unidade anterior, foram fundamentais para a sua compreensão. 
Figura 5: Transcrição da solução do grupo G1

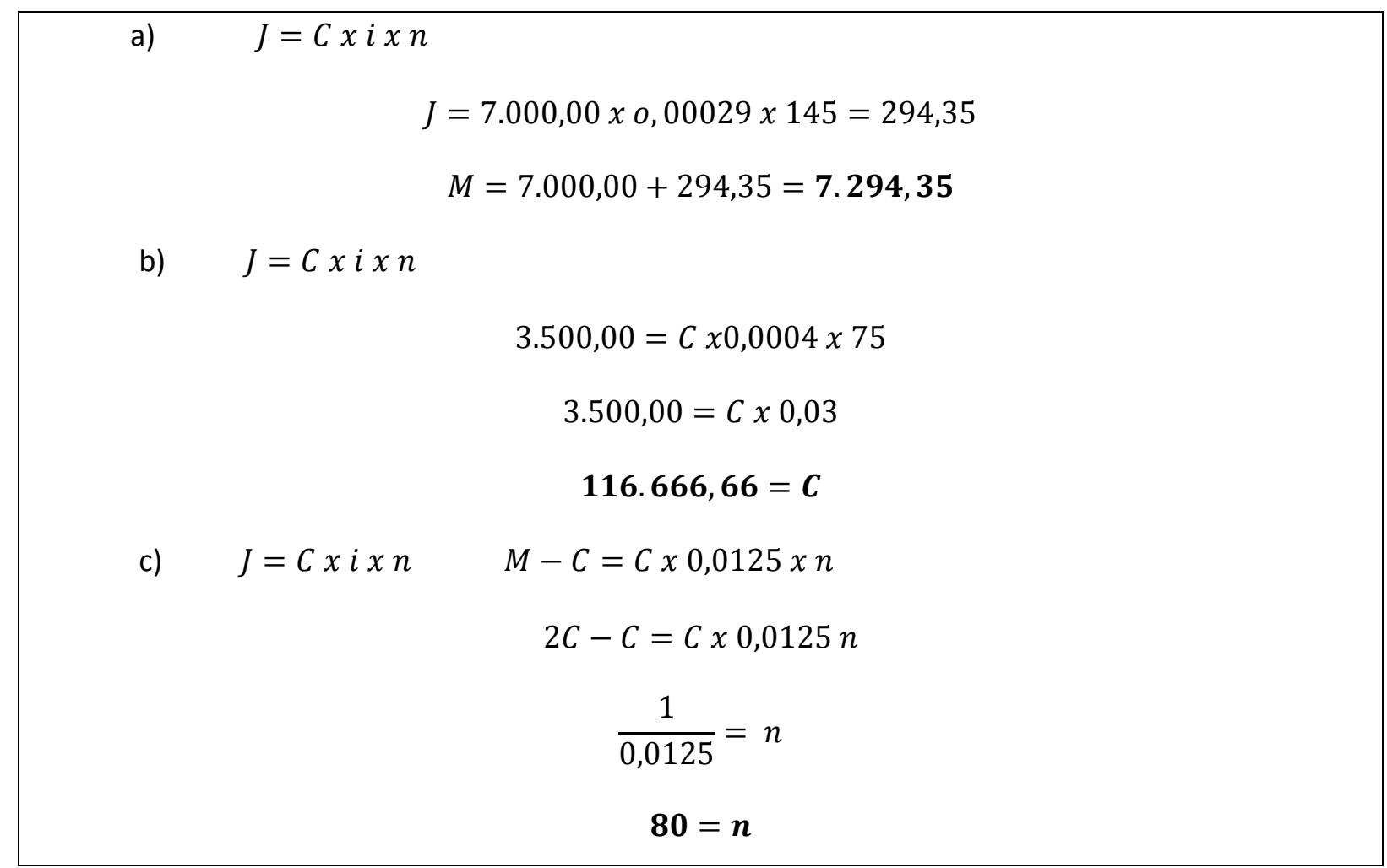

Fonte: Dados do trabalho

$\mathrm{Na}$ plenária, todos os alunos participaram ativamente e foi possível perceber que a maior dificuldade enfrentada por eles está nos cálculos com números decimais. Em geral, os grupos interpretaram corretamente o problema, mas muitos erros foram cometidos no trabalho com números decimais, especialmente na multiplicação e divisão.

Situação-Problema 2: Ângela contratou um empréstimo no valor de $\mathrm{R} \$ 600,00$ a juros compostos de 5\% ao mês. De acordo com esta informação responda:

a) Qual o montante a ser pago após três meses?

b) Se dois meses após a data da contratação Ângela pagasse $\mathrm{R} \$ 200,00$ do saldo devedor, quanto ainda ficaria devendo?

c) Agora considere que, passando-se mais um mês, ou seja, após três meses em relação à data da contratação, ela quitasse o saldo devedor, quanto estaria pagando na quitação? Qual foi o valor do último pagamento? 
No desenvolvimento da atividade observou-se que os grupos não usaram as fórmulas apresentadas nas situações-problema anteriores, mas seguiram o raciocínio mostrado pela professora na plenária, isto é, resolveram passo a passo, como mostra a solução do grupo

Figura 6: Resolução do problema 2 da unidade 2 pelo Grupo 4-G4

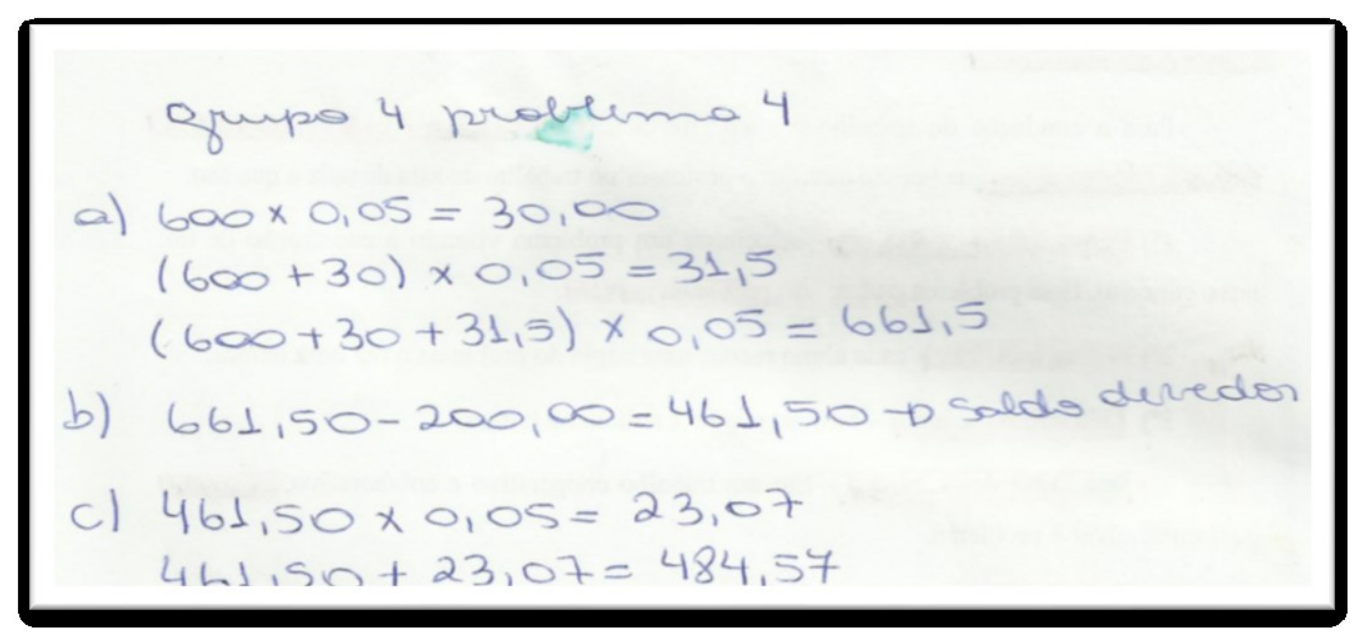

Fonte: dados do trabalho

Os grupos G1, G2 e G3 solucionaram da mesma forma que o G4. Durante a resolução deste problema, os alunos recorreram várias vezes para a leitura do material constante no ambiente MAISUNIFRA.

Situação-Problema 3: Um consumidor resolve comprar um celular que custa $\mathrm{R} \$ 800,00$ à vista. Se preferir, pode parcelá-lo em duas prestações de $\mathrm{R} \$ 400,00$ ou quatro prestações de $\mathrm{R} \$ 200,00$, sendo a primeira parcela paga no ato da compra e considerada como entrada. Sendo que o cliente possui seu dinheiro aplicado à taxa de $1,75 \%$ ao mês, qual será a melhor alternativa de pagamento?

Seguindo as etapas da metodologia de Resolução de Problemas, os alunos iniciaram a busca de uma estratégia com discussões acaloradas. Os grupos foram participativos durante o transcorrer de toda a atividade, trabalhando de forma colaborativa.

A6: Professora nem precisa fazer conta, pela lógica pagar à vista é sempre melhor.

Professora: Reflitam melhor sobre isso.

B2: Correto professora, nós não levamos em conta que o dinheiro está aplicado.

Após essas considerações, os alunos passaram a procurar uma estratégia de solução levando em consideração a aplicação do dinheiro. Na plenária, os alunos expuseram as 
soluções encontradas e observou-se que ainda persistem os erros com cálculos envolvendo números decimais. No quadro, a seguir, apresenta-se a formalização do trabalho de todos os grupos. Um aluno na lousa formalizou a solução da seguinte maneira:

Figura 7: Resolução do problema 3 da unidade 2 pelo Grupo 2-G2

A primeira parcela é a da entrada no valor de $\mathrm{R} \$ 200,00$.

Após 1 mês: foi feito o pagamento da segunda parcela. O saldo de $\mathrm{R} \$ 600,00$ aplicado a $1,75 \%$ rendeu, em um mês, $R \$ 10,50$ :

$$
\begin{gathered}
R \$ 600,00 \times 0,0175=R \$ 10,50 \\
R \$ 600,00+R \$ 10,50=R \$ 610,50
\end{gathered}
$$
saldo de

Após 2 meses: foi feito o terceiro pagamento de $\mathrm{R} \$ 200,00$. Assim, resta um

$$
R \$ 610,50-R \$ 200,00=R \$ 410,50
$$

que aplicado a $1,75 \%$ rendeu $\mathrm{R} \$ 7,18$.

$$
\begin{gathered}
R \$ 410,50 \times 0,0175=R \$ 7,18 \\
R \$ 410,50 x 0+R \$ 7,18=R \$ 417,68
\end{gathered}
$$

Após 3 meses foi feito o quarto pagamento de $\mathrm{R} \$ 200,00$ e resta um saldo de

$$
R \$ 417,68-R \$ 200,00=R \$ 217,68
$$

que aplicado a $1,755 \%$ rendeu $\mathrm{R} \$ 3,80$, ou seja,

$$
\begin{gathered}
R \$ 217,68 x 0,0175=R \$ 3,80 \\
R \$ 217,68 x 0+R \$ 3,80=R \$ 221,48
\end{gathered}
$$

No último pagamento resta ainda um saldo de

$$
R \$ 221,48-R \$ 200,00=R \$ 21,48
$$

Pagando em quatro parcelas foi possível lucrar R $\$ 21,48$.

Fonte: Dados do trabalho

Os alunos ficaram surpresos com o resultado, pois, para eles, o pagamento à vista sempre era a melhor opção. Um aluno concluiu:

A1: "Nesta compra é melhor deixar o dinheiro aplicado e pagar parcelado pois sobre as parcelas não incide juro, isto é, 4 vezes de $R \$ 200,00$ é igual ao valor à vista.

Professora: Entre as duas alternativas de parcelamento qual é a mais vantajosa para o consumidor?

A1:Não será a mesma coisa? 


\section{Professora:Tentem verificar.}

A5: Enquanto a professora atendia o outro grupo eu já calculei e é mais vantajoso parcelar em duas vezes porque, neste caso, economiza-se $R \$ 28,00$ em vez de apenas $R \$ 21,48$.

Com esta atividade, que diz respeito ao cotidiano dos alunos, percebeu-se, pelasdiscussões e exemplos que surgiram durante a plenária, o quanto estavam apropriados com este tipo de problema. Quando questionados pela professora, argumentaram que a maioria tem filhos adolescentes e que este tipo de compra faz parte da rotina deles.

No terceiro encontro foram trabalhados apenas dois problemas, apresentados a seguir:

Situação-Problema 4: Um aparelho de televisão no valor de $R \$ 3480,00$, foi comprado a prazo e quitado 5 meses depois pelo valor de $R \$ 3949,80$. Qual a taxa de juros simples, mensal e anual, que está embutida nessa operação?

Este problema teve como objetivo fazer com que os alunos percebessem o juro que está incluído nos produtos, quando estes são ofertados a prazo.

Logo após a apresentação do problema, um aluno comentou:

$C_{1}$ : Este problema é semelhante a compra que fiz de um aparelho de som. Mas não perguntei ao vendedor que juros eu estava pagando.

Os demais alunos concordaram com o colega e disseram que já haviam passado por situações semelhantes.

Todos os grupos tiveram, inicialmente, dificuldade de encontrar uma estratégia de resolução porque muitos partiram do valor quitado, após 5 meses, como o capital inicial. Foi necessária a mediação da professora em todos os grupos.

Após as discussões nos grupos, foi realizada a plenária e percebeu-se que todos os grupos seguiram a mesma estratégia de resolução. Assim, formalizou-se a solução em conjunto com todos os alunos e que está apresentada a seguir: 
Figura 8: Resolução do problema 4 da unidade 3 pelo Grupo 3

Considerando o preço a vista como $\mathrm{C}_{0}=3480,00$ e o montante após t meses como $\mathrm{C}_{\mathrm{t}}=3949,80$, sendo o tempo $\mathrm{t}=5$ meses, tem-se:

$\mathrm{C}_{\mathrm{t}}=\mathrm{C}_{0}(1+\mathrm{it})$, e, portanto $\mathrm{i}=2,7 \%$ ao mês.

Logo $\mathrm{i}=12 \times 2,7 \%=32,4 \%$ é a taxa correspondente ao ano.

Fonte: Dados do trabalho

Apesar das dificuldades na interpretação e na busca de uma estratégia de resolução, observou-se uma evolução nas discussões entre os alunos de cada grupo e entre os grupos. Muitos lembraram-se de objetos e da forma como foram adquiridos e outros propuseram novas situações que foram aproveitadas pela professora como trabalho complementar.

A última situação-problema apresentada aos alunos teve por objetivo apresentar uma situação em que deveriam considerar os dois tipos de juros, separadamente, e justificar a resposta.

Situação-problema 5: Considerando-se a taxa de juros de $10 \%$ por período, no fim de quanto tempo um capital dobrará de valor? Justifique .

Após a leitura do problema, de forma coletiva e individual, um aluno questionou:

D3: Qual o tipo de juros Professora? Simples ou composto?

Professora: Pensem um pouco. Que possibilidades existem?

$D_{3}$ : Tanto para juros simples como para juros composto a condição $C_{t}=2 C_{0}$, é a mesma, certo?

Professora: Exatamente.

Após os esclarecimentos os grupos trabalharam separando o problema em duas partes, ou seja, calcularam, primeiramente, para juros simples e depois para juros compostos. A seguir, a solução que foi obtida pelos grupos, após a plenária. 
Figura 9: Resolução do problema 5 da unidade 3 pelo Grupo 2

a) Considerando juro simples tem-se:

$\mathrm{C}_{\mathrm{t}}=\mathrm{C}_{0}(1+\mathrm{it}) \mathrm{e}$, portanto $2 \mathrm{C}_{0=} \mathrm{C}_{0}(1+\mathrm{it})$.

Como $\mathrm{i}=10 \%$, segue que $1=\mathrm{t} .10 / 100$

Logo $\mathrm{t}=10$ períodos.

b) Considerando o juro composto tem-se:

$\mathrm{C}_{\mathrm{t}}=\mathrm{C}_{0}(1+\mathrm{i})^{\mathrm{t}}$

Neste caso , $2 \mathrm{C}_{0=} \mathrm{C}_{0}(1+\mathrm{i})^{\mathrm{t}}$ e assim, $2=(1,1)^{\mathrm{t}}$.

Logo $\ln 2=\mathrm{t} \ln (1,1)$ e $\mathrm{t}=0,693 / 0,095$.

$\mathrm{T}=7,29$ períodos

Fonte: dados do trabalho

Na plenária, a professora questionou:

Professora: qual o tipo de aplicação que traz mais vantagem?

B2: A aplicação com juros compostos, pois leva-se menos tempo para dobrar o capital investido.

Professora: por que isto acontece?

A1: porque no cálculo com juros simples sempre parte-se do capital inicial e no composto , considera-se sempre juro sobre juro.

Das respostas dos alunos, percebe-se que eles compreenderam o que é juro simples, juro composto e a diferença entre eles.

\section{Considerações finais}

Para analisar as contribuições que a metodologia de Resolução de Problemas proporcionou à aprendizagem dos conceitos da Matemática Financeira para os alunos envolvidos neste trabalho, buscou-se construir as unidades de ensino com base em uma sequência de problemas que possibilitassem a formalização de tais conceitos.

No decorrer do trabalho, foi possível verificar, nas três unidades desenvolvidas, que os alunos, inicialmente, apresentaram sérias dificuldades para interpretar os problemas propostos, ou seja, não conseguiam analisar o comportamento das soluções encontradas e de trabalhar com a metodologia de resolução de problemas. Na medida em que os problemas foram sendo discutidos e o consenso foi sendo estabelecido, observou-se que todos os grupos conseguiram compreender a formalização dos conceitos trabalhados.

Durante o período de observação e investigação na sala de aula e da análise e discussões dos resultados coletados, foi possível observar ainda as dificuldades dos alunos em 
descrever no material de registro, seus diários de campo, a maneira como resolveram mentalmente os problemas. Isso se deve ao fato de os alunos apresentarem dificuldade de expressar por escrito seus procedimentos de resolução dos problemas propostos. Apesar dessa dificuldade, que foi sendo superada na medida em que as atividades iam sendo apresentadas, acredita-se que os objetivos do trabalho foram atingidos, visto que houve uma forte interação com os alunos. Esta interação ocorreu durante todo o período de realização da pesquisa e, com isso, foi possível observar e identificar a forma como desenvolveram as atividades em sala de aula.

Observando a maneira como os alunos resolveram as situações-problema propostas e analisando os registros escritos de suas resoluções, foi possível verificar que os processos de ensino e aprendizagem foram favorecidos pela relação entre os alunos e também da relação entre estes e a professora, pois ocorreu uma contribuição mútua na aquisição e aprimoramento do conhecimento, o que evidencia a importância de um ensino que favorece o trabalho em grupo.

Isto está de acordo com a afirmação de Pozo e Echeverria (1998):

\begin{abstract}
O papel do professor consiste em preparar o trabalho e orientar o seu desenvolvimento em sala de aula, fazendo tentativas e proporcionando a possibilidade de novas descobertas de resolução, promovendo situações para que o aluno faça perguntas e possa ser orientado para que ele mesmo se aventure em busca de novas respostas. Assim que o aluno tenha uma suposta resposta, a ação do professor será mais eficaz para incentivá-lo à socialização com seus colegas, explicitando os procedimentos utilizados para sua resolução. (p.107).
\end{abstract}

Através deste trabalho investigativo, foi possível constatar que, ao ensinar por meio da resolução de problemas, os alunos puderam utilizar os processos de resolução que os levaram a reorganizar os conhecimentos anteriormente adquiridos relacionados com porcentagem e juros, bem como aqueles relacionados com parcelamento de pagamentos de mercadorias. Além disso, é importante enfatizar também que a aprendizagem destes conteúdos foi favorecida pelo fato de os problemas propostos estarem relacionados com o dia a dia dos alunos, ou seja, as situações propostas estavam de acordo com a realidade da turma.

Enfatiza-se também que ocorreu uma alteração no papel do professor, que deixou de ser o transmissor de conhecimentos para assumir uma posição de mediador, incentivador, estimulador da aprendizagem e promotor da autonomia dos alunos, por meio da abertura à participação dos alunos nas aulas.

O processo de ensino e aprendizagem de Matemática foi favorecido pela maneira como foi conduzido o trabalho na sala de aula, ou seja, durante a investigação os alunos 
estavam divididos em grupos, com a finalidade de resolver problemas voltados a criação e resolução de modelos que envolviam juros simples e porcentagens. Assim, ao buscarem as soluções desejadas para os problemas, eles interagiram entre eles e também com a professora, buscaram interpretar os enunciados dos problemas, e explorar as informações neles contidas para compartilhar o entendimento com os demais colegas do grupo. No processo de resolução, os sujeitos tiveram que interpretar, concordar ou rejeitar as ideias de seus colegas e tiveram que elaborar suas próprias estratégias de resolução. Neste contexto de trocas, todos aprenderam.

\section{Referências}

BRASIL. Lei n. 9.394 de 20 de dezembro de 1996. Estabelece as Diretrizes e Bases da Educação Nacional. Ministério da Educação. Disponível em: $<$ http://portal.mec.gov.br/sesu/arquivos/pdf/lei9394.pdf >. Acesso em 25 out. 2015.

BRASIL. Ministério da Educação. Secretaria de Educação Fundamental. Parâmetros Curriculares Nacionais: Matemática. Brasília, 1998.

BRASIL. Ministério da Educação. Secretaria de Educação Média e Tecnológica. Parâmetros Curriculares Nacionais (Ensino Médio). Brasília, 2000.

DANTE, L. D. Didática da Resolução de Problemas de Matemática. São Paulo: Ática, 1991.

DINIZ, M. I. Os Problemas Convencionais nos Livros Didáticos. In: SMOLE, K. S.; DINIZ, M. I. (Orgs.) Ler, Escrever e Resolver Problemas: Habilidades Básicas para Aprender Matemática. Porto Alegre: Artmed, 2001. Porto Alegre: Artmed, 2001. p. 99 - 102.

FERREIRA, A. P. de O.; NOGUEIRA, C. M. I. ; OLIVEIRA, L. L. A. de. Os recursos didáticos como mediadores dos processos de ensinar e aprender matemática. 2009. Disponível em: <http://www.diaadiaeducacao.pr.gov.br/portals/pde/arquivos/2164-8.pdf $>$. Acesso em: 05 mar. 2016.

MASETTO, M. T., MORAN, J.M.; BEHRENS, M. A. Novas Tecnologias e mediações pedagógicas. Campinas,SP: Papirus, 2007.

ONUCHIC, L. R. Ensino-Aprendizagem de Matemática através da Resolução de Problemas. In: BICUDO, M. A. V. (Org.). Pesquisa em Educação Matemática. SãoPaulo: Editora UNESP, 1999. p.199-220.

ONUCHIC, L. R.; ALLEVATO, N. S. G. Formação de Professores - Mudanças Urgentes na Licenciatura em Matemática. In: FROTA, M. C. R.; NASSER, L. (Orgs). Educação Matemática no Ensino Superior: pesquisas e debates. Recife: SBEM, 2009. p. 169-187.

POZO, J. I., ECHEVERRÍA, M. P. A solução de problemas: Aprender a resolver, resolver para aprender. Porto Alegre: Art Med,1998 
VAN DE WALLE, J. A. Matemática no Ensino Fundamental: formação de professores e aplicação em sala de aula. 6.ed. Porto Alegre: Artmed, 2009.

VIEIRA, C. L. A Matemática Financeira no Ensino Médio e sua Articulação com a Cidadania. 2010. Dissertação (Mestrado em Educação Matemática) - Universidade Severino Sombra, Vassouras, 2010. 